\title{
Adopted Utility Calculus: Origins of a Concept of Social Affiliation
}

\author{
Lindsey J. Powell ${ }^{1}$ \\ ${ }^{1}$ Department of Psychology, University of California, San Diego, San Diego, CA \\ Revised, August 31, 2021 \\ (accepted for publication in Perspectives on Psychological Science)
}

Address correspondence to:

lipowell@ucsd.edu

9500 Gilman Dr. MC 0109

La Jolla, CA, 92093 


\begin{abstract}
To successfully navigate their social world, humans need to understand and map enduring relationships between people: we need a concept of social affiliation. Here I propose that our initial concept of social affiliation, available to human infants, is based on the extent to which one individual consistently takes on the goals and needs of another. This proposal grounds affiliation in intuitive psychology, as formalized in the naive utility calculus model. A concept of affiliation based on interpersonal utility adoption can account for findings from studies of infants' reasoning about imitation, similarity, helpful and fair individuals, "ritual" behaviors, and social groups, without the need for additional innate mechanisms such as a coalitional psychology, moral sense, or general preference for similar others. I identify further tests of this proposal, and also discuss how it is likely to be relevant to social reasoning and learning across the lifespan.
\end{abstract}

\title{
Introduction
}

Human infants are highly motivated to engage and bond with social partners (Rochat et al., 1999; Trevarthen \& Aitken, 2001; Tronick et al., 1978), but how do they understand such bonds? What kinds of relationships do infants attribute, what cues do they use to recognize those relationships, and what predictions do they make on the basis of affiliation? Like adults, infants employ intuitive theories that allow them to generate predictions about and explanations for events involving the objects and agents around them (Baillargeon, et al., 2016; Gelman \& Legare, 2011; Gopnik \& Wellman, 1992; Spelke, 1990; Ullman \& Tenenbaum, 2020). Do they also employ a theory-like framework to reason systematically about social affiliation? If so, is that theory connected to or independent from their intuitive theory of the psychology of individual agents? How does infants' initial theory or concept of affiliation support future learning about more complex or culturally specific social structures and rules?

Here I propose that infants' estimate of the consistent value that one individual places on a particular partner's goals and desires serves as their initial concept of affiliation (Jara-Ettinger et al., 2016; Kleiman-Weiner et al., 2017; Ullman et al., 2009). This definition of affiliation allows infants to use their understanding of rational action to infer not only what others value, but also who they value. When integrated with other components of our commonsense psychology, including an understanding of others' perception, knowledge, capabilities, and effort, this concept would allow infants to infer affiliation from observed behaviors and predict future actions on the basis of known affiliative relationships.

This proposed concept of affiliation has three desirable features. First, it can be integrated with the existing formal instantiation of intuitive psychology, referred to as our "naive 
utility calculus" (Jara-Ettinger et al., 2016; Jara-Ettinger, et al., 2020). Second, it makes strong predictions about infants' expectations of social behavior and affiliation that differentiate it from other proposals focused on homophily (i.e. a preference for similar others) or shared category membership. The predictions of the current account and those of alternative accounts particularly diverge around the possibility that infants could represent asymmetrical social relationships. Third, it minimizes the number of distinct domains needed to explain infants' social reasoning and evaluation. Prominent proposals suggest that infants' understanding of individual agents, of social groups, and of pro- and antisocial behaviors reflect three distinct, foundational domains of social cognition: intuitive psychology, intuitive sociology, and intuitive morality (Hamlin, 2013a; Liberman et al., 2017a; Rhodes, 2013; Shutts \& Kalish, in press; Spelke \& Kinzler, 2007; Ting et al., 2019; Wynn \& Bloom, 2014). Here I argue, to the contrary, that infants' reasoning in all three areas can be understood in a common framework.

\section{Intuitive Psychology and Naive Utility Calculus}

When we observe another individual's actions, we don't focus only on what they're doing - taking a bite of a sandwich, picking up a dirty sock, painting an ocean view - but also on why they're doing it. Our commonsense psychology allows us to attribute goals, knowledge, beliefs, and emotions to others that can both explain their current actions and predict future ones (Baillargeon et al., 2016; Gopnik \& Wellman, 1992; Saxe, et al., 2004). But how do we decide which specific psychological causes to attribute?

One powerful proposal is that the general assumption that others are rational agents seeking to maximize their welfare allows us to reason both forward from a person's goals to their likely actions, and backward from observed behavior to the actor's specific goals and beliefs (Baker, et al., 2017; Gergely \& Csibra, 2003; Woodward, et al., 2001). If you walk to the taco truck three blocks away for lunch, instead of getting a sandwich from the shop next door to your house, I can infer from the additional effort you put into the task of getting lunch that you prefer tacos to sandwiches (Baker, et al., 2009; Liu, et al., 2017).

This approach to intuitive psychology has been formalized in the proposal of a "naive utility calculus" (Jara-Ettinger, et al., 2016; Jara-Ettinger, et al., 2020). This computational model lays out how an observer expects an actor to calculate the utility of an available action as the difference between the expected reward of the outcome and the expected cost of the action (Figure 1). Both the reward and cost variables are agent-specific, accounting for the fact that different agents may find an outcome more or less rewarding, and an action more or less difficult. Given the stipulation that agents will tend to choose the actions that maximize their overall utility (i.e. produce the largest difference between reward and cost), this model supports 
A simplified version of the Naive Utility Calculus:

$$
\begin{aligned}
\text { Utility(Action,Outcome) } & =\text { Reward(Outcome) }- \text { Cost(Action) } \\
U & =R(O)-C(A)
\end{aligned}
$$

\begin{tabular}{|l|l|} 
Adopted Utility Calculus: Agent A is affiliated \\
with Agent B to the extent that Agent A will act to \\
promote Agent B's rewards across interactions \\
like the ones sketched below. This likelihood is \\
determined by the weighting parameter, w.
\end{tabular}

Ways in which Agent A's utility may or may not take Agent B into account:

$\begin{array}{lll}\text { Individual Action } & U_{A}=R\left(O_{A}\right)-C\left(A_{A}\right) & \begin{array}{l}\text { Agent } A \text { places value on achieving their own } \\ \text { goals }\end{array} \\ \text { Helping } & U_{A}=W_{B}{ }^{*} R\left(O_{B}\right)-C\left(A_{A}\right) & \begin{array}{l}\text { Agent } A \text { places value (scaled by weight } w) \\ \text { on the rewards of Agent } B\end{array} \\ \begin{array}{lll}\text { Cooperation, } \\ \text { Prosocial imitation }\end{array} & U_{A}=W_{B}{ }^{*} R\left(O_{A+B}\right)-C\left(A_{A}\right) & \begin{array}{l}\text { Agent } A \text { places value on achieving a } \\ \text { common reward with Agent } B\end{array} \\ \text { Learning, Competing } & U_{A}=R\left(O_{\not \rightarrow A}\right)-C\left(A_{A}\right) & \begin{array}{l}\text { Agent } A \text { places value on achieving a reward } \\ \text { associated with Agent } B \text { for themselves }\end{array}\end{array}$

Group affiliation $\quad U_{A}=$ Wa.g.m. $^{*} R\left(O_{B}\right)-C\left(A_{A}\right) \begin{aligned} & \text { Agent } A \text { places value on the rewards of all } \\ & \text { group members (a.g.m.), including Agent } B\end{aligned}$

\section{Prosocial disposition $\quad U_{A}=$ Wa.s.p. ${ }^{*} R\left(O_{B}\right)-C\left(A_{A}\right)$ Agent $A$ places value on the rewards of all social partners (a.s.p.), including Agent B}

The full utility for a specific action may have multiple reward components, e.g.:

$$
U_{A}=R\left(O_{A}\right)+W_{B}{ }^{*} R\left(O_{B}\right)-C\left(A_{A}\right)
$$

Agents compare full utilities for candidate actions and select the action with the highest utility

Figure 1. A sketch of the naive utility calculus implementation of commonsense psychology (Jara-Ettinger, Gweon, Schulz \& Tenenbaum, 2016), and different inferences an observer could make regarding one individual's integration of another's rewards into their own utility function. The "adopted utility" concept of affiliation proposes that infants' understanding of affiliation is centered on an inference of the stable weight that one agent places on another's rewards; the higher this weight, the more likely the first agent is to act in ways that altruistically or cooperatively promote the goals of the second.

psychological reasoning. The observer can use known rewards and costs to predict an agent's actions, or infer rewards and costs from observed action choices.

Adults, children, and infants have all been shown to reason in ways that conform to the predictions of this naive utility calculus (Baker et al., 2017; Jara-Ettinger, Gweon, et al., 2015; Jara-Ettinger et al., 2020). In the case of infants, there are at least four related lines of evidence. First, infants infer preferences on the basis of observed choices between known options 
involving equal cost actions (e.g. Luo \& Baillargeon, 2007; Luo \& Johnson, 2009; Woodward, 1998). Second, infants infer preferences on the basis of the amount of effort put toward achieving different outcomes (Liu et al., 2017). Third, infants expect pursuit of an attributed goal to be as efficient as possible (Csibra, et al., 1999; Liu, et al., 2019; Scott \& Baillargeon, 2013; Skerry, et al., 2013). And fourth, infants expect an agent who has achieved a goal to have a congruent emotional response: to be happy (Skerry \& Spelke, 2014).

\section{The Calculus of Prosocial Behavior}

The intuitive psychology encoded in the naive utility calculus also offers a route to identifying helpful behaviors. If one individual acts in a way that primarily serves as an efficient means of promoting someone else's goal, that suggests the actor has incorporated the other person's goal into their own utility function (Figure 1; Hamlin, Ullman, et al., 2013; Ullman et al., 2009). Imagine you're trying to take dirty clothes into a laundry room, but the door is closed and your hands are full with the basket. If I open the door, wait for you to go through, and then close it behind you, those actions don't move me toward a reward, but they do allow you to achieve your goal. Thus, a rational interpretation of my behavior is that I cared enough about your goal that I was willing to put in some effort to help you achieve it.

Empirical evidence suggests infants identify helpful behavior in this way. The majority of studies find that infants prefer helpful individuals to those who hinder others' goals (Hamlin, et al., 2007; Hamlin \& Wynn, 2011; Hamlin, et al., 2011; Margoni \& Surian, 2018; Woo \& Spelke, 2020a; though see Salvadori et al., 2015; Schlingloff, et al., 2020). This preference extends to those who intend to be helpful, even if they are not successful (Hamlin, 2013b). It also only applies to helpers who know their efforts are promoting another's desired outcome (Hamlin, Ullman, et al., 2013; Woo \& Spelke, 2020b). Thus, infants can single out cases in which an actor knowingly puts effort into promoting another's goal, even if that effort fails.

Considering the broader scope of prosocial behavior, cooperation could be identified via the same framework. In acts of cooperation, each actor exerts effort so that all cooperators can share in the rewarding outcome together, holding off on individual success until the collective goal is complete (Hamann et al, 2012; Kleiman-Weiner et al., 2016). A cooperator's utility is thus determined both by their own reward and that of their cooperative partner(s) (Figure 1).

\section{Adopted Utility as a Core Component of an Affiliation Concept}

The cost one person will pay to promote another's rewards often depends on their relationship: we care more about the welfare of those we're close to (Delton \& Robertson, 2016; Fehr et al., 2008; Jones \& Rachlin, 2006). A concept of affiliation centered on this feature can be built atop the naive utility calculus by positing that observers can infer a stable weight that 
one actor places on the rewards of a particular social partner ("w" in Figure 1; see also Kleiman-Weiner et al., 2017). The higher this weight, the more "affiliated" the actor is with the social partner, and the more likely they are to maximize their own utility by engaging in costly actions that benefit the social partner, at least in the mind of the observer making the attribution of affiliation. ${ }^{1}$ In more colloquial terms, infants may conceive of affiliation as the probability that one individual will put effort into promoting the welfare of another. I will refer to this definition as the "adopted utility" concept of affiliation.

Seeing one individual help another would provide evidence that the helper is affiliated with, i.e. values the rewards of, the recipient. The more frequent or costly the help infants observe one agent providing to the other, the stronger the inference of affiliation should be. Inferences of affiliation should support infants' expectations of support, as well as other affiliative behaviors such as approach or positive emotional expressions. Observing cooperation could similarly provide evidence of the affiliative ties between social partners.

\section{Adopted Utility and Prosocial Imitation}

Shifting from thinking about single prosocial acts to thinking about social partners' stable weighting of one another's goals has implications for thinking about another type of behavior that often plays a positive role in social interactions: social imitation or alignment. This refers to cases in which one social partner mirrors another's voluntary actions, gestures, expressions, speech, or choices (Chartrand \& Bargh, 1999; Chartrand \& Lakin, 2013; Meltzoff, 1990; Over \& Carpenter, 2012; Over, 2020). The prosocial role of imitation has often been attributed to the evidence it provides of similarity between the model and imitator (Chartrand \& Bargh, 1999; Haun \& Over, 2015).

An alternative basis for the prosocial meaning of imitation, however, may stem from its potential to reflect a motivation to value a partner's goals. Social interactions do not always occur in contexts in which one or more interaction partners have unfulfilled goals that provide a basis for helping or cooperation. And yet, each individual participant makes a variety of behavioral choices within a given interaction: which words they use, what ice cream flavor they order, whether they put on their jacket or cross their arms. Each of these behaviors indicates some expected reward on behalf of the actor, however minor. If the other partner in the interaction reliably places value on the actor's rewards when choosing their own actions, that social partner is more likely to end up aligning with some number of those behaviors. Thus even in the absence of unmet goals, affiliated individuals can adopt one another's rewards as a result of their underlying propensity to share utility.

${ }^{1}$ A similar approach would be to propose that infants track others' welfare tradeoff ratios (Delton \& Robertson, 2016; Howard et al., 2018). 
The point is not that imitation directly benefits the model; imitation does not typically enhance the model's individual success, so it is not akin to helping in this way. (Although its potential to constitute a joint goal, akin to cooperation, may be rewarding to both parties [Figure 1; Tomasello et al., 2005; Warneken \& Tomasello, 2007]). Instead, I propose that imitation is viewed as prosocial when it can be interpreted as evidence for the imitator's high, stable weighting of the utility of the model (i.e. "w" in Figure 1; see below for a discussion of factors that disambiguate other motives for imitation.)

Below, I describe how the proposed concept of affiliation fits existing research on infants' social reasoning, as well as additional predictions it makes. I also contrast it with proposals that base affiliative understanding in similarity or social categories.

\section{Adopted Utility Calculus and Asymmetrical Representations of Affiliation}

One feature of the adopted utility model of affiliation is that its most basic form is asymmetrical. Just as an agent's preference for tacos doesn't imply anything about tacos' affinity for the agent, one agent's tendency to adopt the utility of a particular social partner does not entail reciprocation. Thus, the simplest affiliative inferences may encode only that an agent who helps or aligns is affiliated with the target of those behaviors, and not vice versa. This is consistent with the range of human relationships. While many relationships are roughly reciprocal, asymmetries in affiliation do exist (Baumeister \& Leary, 1995; Fiske, 1992; Vaquera \& Kao, 2008). Infant-caregiver relationships are a good example: despite mutual attachment, the caregiver's frequent adoption of the infant's welfare is typically not reciprocated.

Asymmetrical representations of affiliation are at odds with most other theories of infants' and young children's understanding of affiliation, however, which focus on similarity or social groups (e.g. Dunham, 2018; Haun \& Over, 2015; Liberman et al., 2017a; Rhodes, 2013; Shutts \& Kalish, in press; Ting et al., 2019). When two individuals share a characteristic or act alike, group- or similarity-based concepts of affiliation predict symmetrical inferences of each individual's affiliation with the other. Thus, an important test of the adopted utility proposal is to ask whether early inferences of affiliation are asymmetrical in relevant circumstances.

\section{Imitation}

Some evidence of asymmetrical affiliative inferences in infancy comes from research on infants' third party observations of imitation. In one series of experiments, infants were familiarized to interactions between a central character and two different social partners. In some experiments, each of the social partners began the interactions by jumping and making a unique sound. When responding to one social partner, the central character imitated the partner's sound; when responding to the other partner, the central character did not imitate 
(Figure 2a). Infants then saw test trials in which the central character alternately approached the partner it imitated and the one it did not imitate. Across age groups, infants expected the central character to approach the partner it imitated, and looked longer when that character approached the non-imitated partner instead (Powell \& Spelke, 2018a, Exps 3, 4, \& 5; Figure 2c). In contrast, if infants were familiarized to the central character being imitated by one social partner and not the other, their looking times no longer indicated that they expected the central character to approach the partner who had imitated it over the one who had not (Powell \& Spelke, 2018a, Exp 4; Figure 2g). Thus, infants selectively used patterns of imitation to infer the social affiliation of the central character when it was the responding agent -- the agent who adopted one social partner's goals but not the other's -- while making no inferences about the character's affiliation when it was the target of utility adoption.

Infants' own imitation-based preferences show a similar asymmetry. Following the same types of dyadic events described above, infants were given preferential looking tests for the two social partners involved exclusively in imitative or non-imitative interactions (i.e. not the central character). When this constituted a choice between an imitator and a non-imitator, infants were more likely to look at or reach for the imitator over the non-imitator (Figure 2h; Powell \& Spelke 2018b, Expts 1 \& 2; see also Powell \& Spelke, 2017; Thomas, Saxe \& Spelke, 2020). In contrast, when the choice was between an imitated character and one that had not been imitated, infants showed no preference (Figure 2d; Powell \& Spelke, 2018b, Expt 3). Infants' positive evaluations of imitation therefore selectively apply to individuals who intentionally adopt the goal of their social partner, and not to those whose goals are adopted.

Both the inferences and evaluations described above are incompatible with the typical interpretation that imitation enhances social affiliation because it taps into homophily (Meltzoff, 1990; Chartrand \& Bargh, 1999; Haun \& Over, 2015). The homophily interpretation is based on research showing that adults and children prefer those who are similar to themselves and infer that similar others are likely to be affiliated (Afshordi, 2019; Billig \& Tajfel, 1973; Byrne \& Griffitt, 1966; Fawcett \& Markson, 2010; Liberman \& Shaw, 2019; Roberts et al., 2017; Shutts, Roben, et al., 2013). To the extent that imitation shows the imitator and model to be similar, it should thus predict symmetrical liking between the two social partners, but be irrelevant to others' social preferences. Instead, we found that infants infer only the imitator's affiliation, and prefer the imitator despite a lack of similarity to themselves.

\section{Similarity}

Other research has aimed to directly test infants' feelings and expectations of homophily, but the results of these studies may be equally or better accounted for by asymmetrical 
Single responder aligns with one of two targets:

a) Imitative interaction:

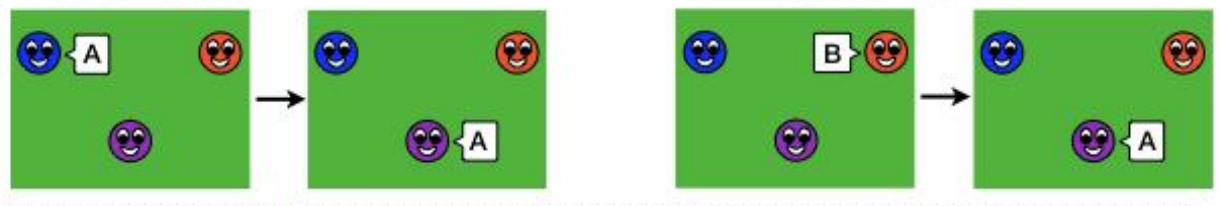

b)

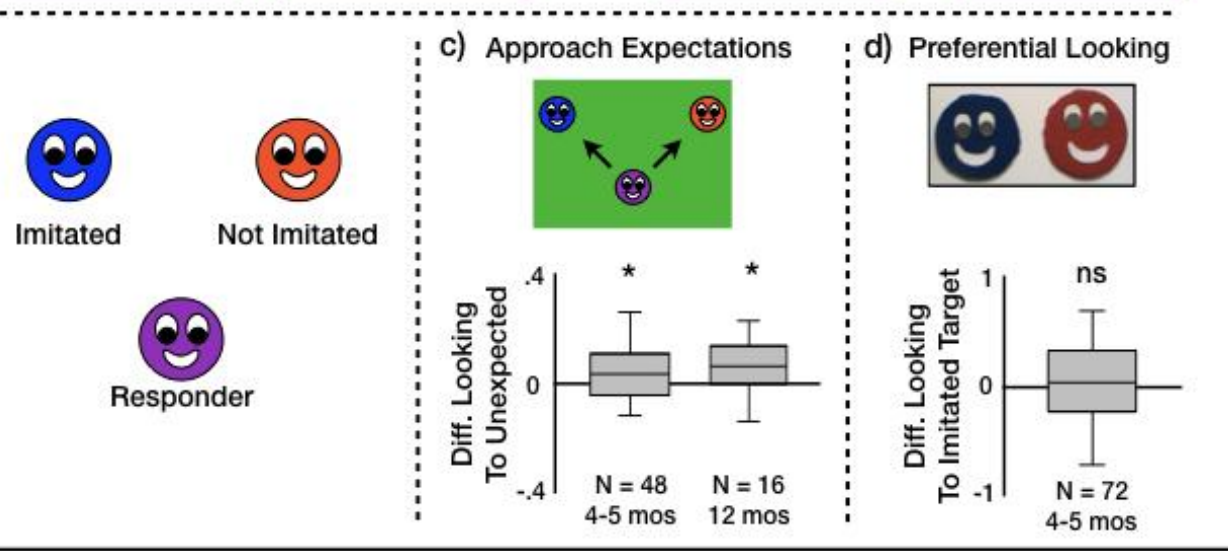

One responder aligns with target; the other does not align:

e) Imitative interaction:

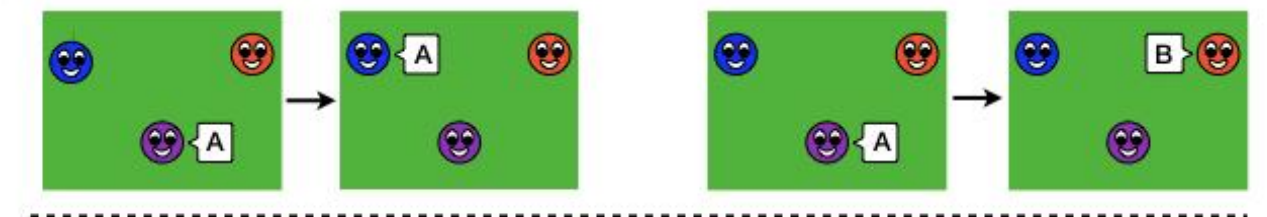

f)

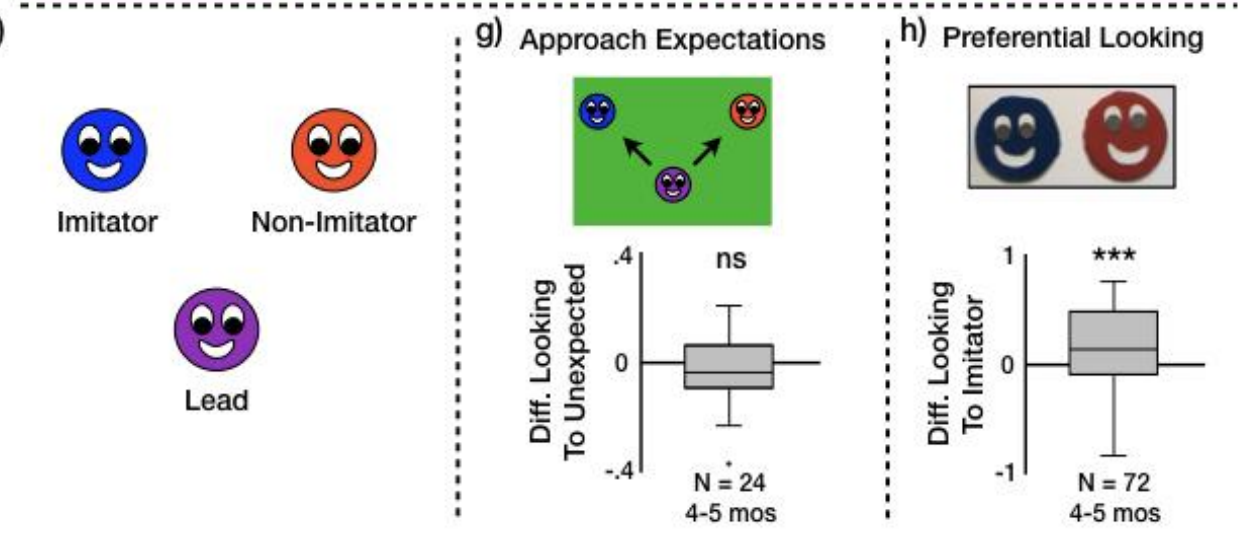

Figure 2. Displays and results from selected experiments in Powell \& Spelke, 2018a, and Powell \& Spelke, 2018b. a) Some participants saw interactions with one responder (purple), who imitated one social partner but not the other, resulting in b) one imitated target and one non-imitated target. c) These participants expected the responder to approach the target it imitated rather than the one it did not at 4-5 months (Powell \& Spelke, 2018a, Expts 4\&5) and 12 months (Powell \& Spelke, 2018a, Expt 3), but d) did not show a preference for the imitated target (Powell \& Spelke, 2018b, Expt 3). e) Some participants saw interactions with two responders (red \& blue), one who imitated the purple target and one who did not, resulting in $\mathrm{f}$ ) one imitator and one non-imitator. g) These participants did not have expectations about who the target would approach at 4-5 months (Powell \& Spelke, 2018a, Expt 4; 12 mos not tested), but h) did show a preference for the imitator over the non-imitator (Powell \& Spelke, 2018b, Expts 1\&2). These results support the hypothesis that infants focus on agents who adopt others' goals when inferring affiliation and forming preferences. All looking coded as proportional difference scores, e.g. (Look unexpected Look $\left._{\text {expected }}\right) /\left(\right.$ Look $_{\text {unexpected }}+$ Look $\left._{\text {expected }}\right)$. 
inferences based on the adopted utility concept of affiliation. In one study evaluating infants' own homophily, 11-month-old participants were given a choice between one puppet who expressed a preference for the same food that the participant preferred and another that expressed a contrasting preference (Mahajan \& Wynn, 2012, Expt 1). Infants were more likely to reach for the puppet who shared their preference, but only if the infant had chosen first; if the puppets expressed preferences first and then the infant chose between the foods, they were equally likely to reach for the puppets with similar and dissimilar preferences. In another experiment, infants' preference for a similar social partner was also limited by active choice: infants preferred a puppet who had the same color mittens as the infant, but only if both the infant and puppet had chosen their mittens. If mitten colors were assigned by the experimenter, infants did not have a social preference (Mahajan \& Wynn, 2012, Expt 2). The authors interpret these two results as demonstrating that similarity preferences arise 1) only when the infants' own preferences are salient, and 2) only for some kinds of similarity. The adopted utility calculus provides a more parsimonious account: infants prefer individuals who intentionally, prosocially align with the infants' own expressed utility, but otherwise do not care about similarity. The same explanation can apply to evidence that infants prefer those who help puppets "similar" to themselves (Hamlin, Mahajan, et al., 2013); in that work similarity was also established via the puppet adopting the same food preference the infant had already displayed.

A related line of work asserts that infants use similar behaviors and preferences to infer affiliation between others (e.g. Liberman, et al., 2014; Liberman et al., 2017b; Liberman, et al., 2018). In these studies, one individual expresses a preference or speaks in a particular language, and then a second individual, present throughout (though see below for discussion of Liberman et al., 2021), either matches the first individual or contrasts with them, expressing a different preference or speaking a different language. Then, both individuals engage with one another or disengage. Generally, infants look longer when similarly behaving individuals disengage, and when dissimilar individuals engage. Though these patterns are interpreted as expectations that similar others are more likely to be mutually affiliated, they are also consistent with an asymmetrical inference of affiliation based on adopted utility: infants' looking may be driven entirely by an expectation that the second individual (i.e. the one who did or did not align with the first individual's preference or behavior) will want to engage or disengage with the first individual, without holding any expectation about the affiliative stance of the first individual.

\section{Helping}

What about infants' inferences of affiliation from helpful behavior; are these also asymmetrical? Not all of the relevant data have been collected yet. Studies investigating infants' 
responses to helping find that infants as young as 3-to-6 months of age prefer helpful agents over hindering ones (Hamlin et al., 2007; Hamlin \& Wynn, 2011; Hamlin, 2013b). However, infants this age do not expect the recipient of help to prefer or affiliate with the helper over the hinderer (Kuhlmeier, et al., 2003; Hamlin et al., 2007). One interpretation of this discrepancy is that evaluations of helping emerge earlier than the use of these behaviors for affiliative inferences. An alternative interpretation, based on the adopted utility concept of affiliation, is that helping behaviors do not offer direct evidence about the affiliation of the recipient, but do provide evidence that the helper has an affiliative stance toward the recipient. Just as young infants expect an individual to approach the social partner they imitated over one they did not (Powell \& Spelke, 2018a), they may also expect an individual to approach a social partner they helped over one they hindered. Studies testing this possibility have not yet been run; they will provide an important future test of the concept of affiliation proposed here.

\section{Other Asymmetries}

The inferences and evaluations infants generate in response to other types of social interactions are also consistent with the use of an asymmetrical utility adoption framework to think about affiliation. For example, infants encode who gives to whom, and expect such behavior to be repeated, but not to be reciprocated or to generalize to new recipients (Tatone, Geraci \& Csibra, 2015). When witnessing conflict, infants show a preference for the individual who yields and allows the other to achieve their goal (Thomas \& Sarnecka, 2019). Like the rest of the evidence discussed above, these findings suggest infants are acutely sensitive to which social partner acts on behalf of another.

\section{Support for Preferences Based on Third Party Observation}

A question arises when we consider the experiments described above: why do infants themselves establish social preferences based on third party observations? It would be rational for infants, and people of all ages, to prefer to engage with social partners they expect to adopt and further their own goals. But why prefer those who have provided evidence of their tendency to promote others' goals, even when those others are strangers to the infant?

Some have argued that infants' third party preferences following observations of proand antisocial behavior reflect an innate morality (Hamlin, 2013a; Kanakogi et al., 2017; Ting et al., 2019; Wynn \& Bloom, 2014). On this view, infants are prepared to recognize some behaviors as inherently good and worthy of approval or reward, and others as inherently bad and worthy of sanction, perhaps because such a moral sense promotes survival-enhancing cooperation. Their preferences for prosocial actors would reflect these moral judgments. 
I argue, however, that this sort of innate morality is not necessary to explain infants' third party social preferences. Instead, there are two complementary routes to third party preferences that are both consistent with the adopted utility calculus model of affiliation.

\section{Sympathy-Based Utility Alignment}

The first route does posit that infants possess some morally relevant innate systems, but proposes that these systems primarily take the form of a sympathetic motivation to see others' needs met (Davidov, et al., 2013; Hepach et al., 2013; Roth-Hanania et al., 2011; Warneken \& Tomasello, 2009). Infants and young children show expressions of concern and signs of arousal, such as pupil dilation, in response to others' struggles (Hepach, et al., 2012; Roth-Hanania et al., 2011; Vaish et al., 2009), and, as soon as they are able, will put effort toward achieving others' goals, even when this help is difficult to provide or unobserved (Warenken, et al., 2007). Simply seeing the needy individual helped, despite not being the source of help, also seems to satisfy this motivation (Hepach et al., 2012).

Helping entails adopting the goals not just of the recipient of the help but also, by default, anyone else who wants to see that individual helped. Once the sympathetic infant has adopted a needy individual's goal as part of their own utility function, an agent who helps the needy individual is, in effect, promoting the infant's utility as well. Thus, infants may end up liking helpers not through a recognition of some behaviors as inherently morally good, but rather because helpers share the infants' own altruistic goals; this goal overlap may be interpreted as a potential basis for affiliation.

\section{Inferences of Universal Affiliation and Preferences for Fairness}

What about cases in which there is no cause for an observer to sympathize with someone in need? For example, why do infants develop a preference for those they observe imitating others? We are left again with the question of why this case of observed utility adoption is considered relevant to an infant's own welfare, or how a preference for imitators could enhance infants' fitness.

One possibility is that when infants observe an act of utility adoption, they consider two alternative explanations. One explanation is that the utility-adopting agent, Agent A, is specifically affiliated with the individual whose goal they are acting toward, Agent B. Agent A's alignment with Agent B reflects their enduring, positive weighting of Agent B's rewards within their own utility function, but does not predict Agent A's prosocial behavior towards any other agents. The alternative explanation for the observed prosocial act is that Agent A's alignment with Agent B reflects the fact that Agent A places some weight on the rewards of all potential social partners (Figure 1). This account predicts that Agent A will also adopt the utility of other 
social partners, including the observer, forming a basis for social preference. The adopted utility concept of affiliation could thus be used to attribute a general affiliative stance, which would function like a trait attribution of prosociality and benefit infants and children by helping them identify the most benevolent caregivers (Hamlin, Ullman, et al., 2013; Jara-Ettinger, et al., 2016). These alternatives are not mutually exclusive, though the attribution of one type of affiliation lessens the need for the other in order to explain observed prosocial behaviors.

Infants and young children may have a higher prior expectation of general affiliation or benevolence than older children and adults, increasing the likelihood of social preferences based on third party observation. This hypothesis is consistent with findings that infants will both ask for help from and offer help to others despite short periods of acquaintance (Barragan \& Dweck, 2014; Ramenzoni \& Liszkowski, 2016; Warneken \& Tomasello, 2006), and that they often expect adults to comfort distressed infants (Jin, et al., 2018; Johnson, et al., 2007). Younger children also overestimate how generous others will be toward themselves or non-friend peers, and sometimes predict egalitarian behavior toward outgroups (DeJesus, et al., 2014; Paulus \& Moore, 2014; Smith et al., 2013). In contrast, older children expect others to be more stingy toward those they do not have relationships with, and robustly predict parochial social behavior (DeJesus et al., 2014; Paulus \& Moore, 2014; Smith et al., 2013; ). Given this developmental trajectory, social preferences based on third party observations (at least in the absence of participants' own sympathetic motives) may diminish at the group level with age, as expectations of parochial behavior increase. It should be noted that inferences tying prosocial behavior to a general affiliative stance could be strong enough to support preferring a helper to a hinderer (who definitely does not take a prosocial stance toward all), without necessarily supporting a strong expectation that the prosocial behavior will extend to a specific new social partner (Tatone et al., 2015).

Features of an observed prosocial behavior can impact the relative plausibility of specific versus broad affiliative motivation. In particular, when an actor is faced with multiple possible targets whose welfare they could promote, broad affiliation predicts that the actor ought to help each target as equally as possible, as the actor weights each target's rewards in their utility function to the same extent (Shaw, 2013). In contrast, a specific affiliation would predict favoring one recipient over the others (Shaw et al., 2012). To the extent that infants' third party social preferences are based on the inference that a broadly affiliative actor might also adopt the infants' own goals and utility, they should thus prefer impartial agents over those who show bias toward particular social partners, even if those individuals are equally generous. 
This prediction is born out in research on infants' preferences for fair over unfair distributors. Evidence suggests infants prefer those they observe distributing resources fairly, and expect others to do so as well (Burns \& Sommerville, 2014; DesChamps, et al., 2016; Geraci \& Surian, 2011; Lucca, et al., 2018; Meristo \& Surian, 2013; Strid \& Meristo, 2020). There is also evidence that, without information on prior relationships between individuals, infants expect resources to be distributed fairly (Dawkins, et al., 2019; Meristo, et al., 2016; Schmidt \& Sommerville, 2011; Sloane, et al., 2012; Sommerville, et al., 2013; Ziv \& Sommerville, 2017). When they do have information about affiliation, infants expect giving to be biased according to those relationships, consistent with selective utility adoption (Bian, et al., 2018).

\section{Disambiguating Affiliation From Other Motives for Imitation}

While it may be ambiguous whether helpful acts represent either partiality or universal benevolence, acts of imitation can be ambiguous as to whether they are prosocial at all. In some cases an agent observes someone else's goal and then wants to achieve that desired outcome for themselves. Imitation in such cases should not be considered prosocial or affiliative. If the outcome is not zero sum, we might consider this a case of social learning or influence. If the outcome is zero sum, this constitutes competition (Figure 1). There are also cases in which two individuals choose similar actions due to coincidence or common constraint.

Inferences made via the naive utility calculus can distinguish prosocial imitation from coincidence, social learning, and competition because they specify whose reward state contributes to an agent's utility: their own, someone else's, or both. When one agent repeats the behavior of another, aspects of their actions, aspects of the situation, and observers' prior expectations may all influence the observer's inferences regarding whose rewards are being prioritized, and thus what type of imitation or social interaction is being observed. These sources of information should thus guide the interpretation of copying as prosocial, neutral, or antisocial in intent, and impact the observer's evaluation of the imitator and their inferences of affiliation. Here I discuss specific factors that disambiguate prosocial imitation from coincidence, social learning, and competition within the adopted utility framework.

\section{Coincidence}

In order for imitation to be motivated by a prosocial desire to enact a goal together with the model (i.e. cooperatively), the imitator must know what the model's goals are. Thus, information about perceptual access can distinguish between coincidental and affiliative imitation: if the "imitator" did not observe evidence of the model's goal, then their repetition of the goal must have occurred for some other reason and should not license affiliative inferences or social evaluation (Mahajan \& Wynn, 2012; Olson \& Shaw, 2011; Powell \& Spelke, 2017). Even 
if an actor is aware of another's behavior, they might duplicate the other's actions not through utility adoption but because they already had a similar goal themselves, a possibility made more likely by universally rewarding outcomes or situational constraints (Hurwitz, et al., 2019; Pesowski, et al., 2020). Determining whether imitation reflects a coincidence or intentional utility adoption may be one reason why the targets of imitation sometimes perform "testing behaviors": unusual or unpredictable actions that are unlikely to be independently selected by a social partner (Berger \& Ingersoll, 2015; Carpenter, et al., 2013; Meltzoff, 1990).

\section{Social Learning}

Prosocial imitation primarily occurs in contexts in which the imitator and model are interacting with one another. In contrast, if the imitator observes the model's actions and then replicates them on their own, this is more likely an episode of social learning, in which the imitator is attempting to enhance their own utility by doing what the model did (Laland, 2004). If two friends go to a café and both order the same drink, they can be thought of as having coffee together. On the other hand, if one patron observes the patron in front of them order an unusual drink and then decides to order it themselves, this is better interpreted as the imitator attempting to learn a new potential reward from the model. Infants are capable of using cues such as proximity, orientation, and contingency to recognize social interaction (Beier \& Spelke, 2012; Fawcett \& Gredeback, 2013; Papeo, et al., 2020; Powell \& Spelke, 2013; Thiele et al., 2021), and it is plausible that these cues impact the inferences they make from observations of imitation. The influence of interaction context may also explain affiliative parallel play (Bakeman \& Brownlee, 1980; Parten, 1933; Rubin, et al., 1978): so long as their social cues establish that they are engaged in a joint interaction, children's play need not depend on one another's actions for success in order to encompass a shared goal.

A second factor that impacts the plausibility of affiliative versus learning motivations for imitation is the utility of the action for the imitator. The more plausible it is that the imitated action serves to maximize the imitator's individual utility, the more likely the imitation reflects an act of social learning rather than affiliation. Imitation of actions with a clear instrumental function - that enhance success or efficiency in the pursuit of individual goals - should thus be taken as weaker evidence of affiliation (Deutsch \& Gerard, 1955; Carpenter, 2006; Over \& Carpenter, 2012; Uzgiris, 1981). In contrast, imitation of idiosyncratic preferences and imitation of inefficient actions should be a better signal of affiliation (Over \& Carpenter, 2009; Schachner \& Carey, 2013; Watson-Jones, et al., 2016). The adopted utility framework thus accounts for the fact that shared ritualistic actions, which are by definition inefficient means toward instrumental goals, are treated as superior evidence for social affiliation, without the need for a 
specially evolved "ritual stance" (Liberman, et al., 2018; Watson-Jones \& Legare, 2016). This factor may also explain why parents' imitation of their infants is readily interpreted as affiliative: infants' clumsy and strange vocalizations and expressions clearly aren't good models of how their parents ought to act, but do serve as temporary foci of adopted utility for the interacting parent-infant pair (Hsu \& Lavelli, 2005; Moran, et al., 1987; Papoušek \& Papoušek, 1989).

Finally, high-fidelity imitation as a learning strategy is rare in infancy but becomes more common throughout childhood (Hoehl et al., 2019; Nielsen, 2006; McGuigan \& Whiten, 2009). Children's own experience with imitative learning may increase the tendency to interpret observed copying in this way, whereas infants may primarily view imitation as affiliative.

\section{Competition}

Although social imitation often occurs in the context of positive social interactions, it can also occur in competitive contexts, as competitors act to block or beat one another's goal pursuit (Naber, et al., 2013). Thus, just as mimicry can reflect affiliative utility adoption, perhaps it can also reflect antagonistic relationships (Belot et al., 2013; Cook et al., 2011). Accompanying social behaviors, including positive or negative emotional cues, could help distinguish the intent underlying social mimicry. In addition, situational factors and baseline expectations of competition vs. cooperation may guide interpretation of ambiguous imitative behaviors in one way or another. This may account for some cases in which different individuals have bimodal responses to social imitation. For example, Carpenter, Uebel, and Tomasello (2013) conducted a study in which an experimenter first followed each toddler participant around a playroom, either mimicking the toddler's play or merely playing next to them. Then they gave the toddler a chance to help with a simple goal (e.g. picking up an out of reach object). Amongst the sample who completed the study, imitated toddlers were more likely to help. However, 20\% of recruited participants were uncooperative during the initial play phase, and all but one of these fussy participants were in the imitation condition. One possibility is that this subset of participants construed the experimenter's imitation as reflecting a competitive or antagonistic stance, while the remaining participants interpreted the same goal matching as affiliative.

\section{Building Social Groups From Individual Affiliation}

Asymmetrical, dyadic caregiving relationships are central for infants. However, much of human social life is built around reciprocal affiliation and membership in social groups (Bowles \& Gintis, 2011; Dunham, 2018; Fehr \& Fischbacher, 2003; Trivers, 1971). The adopted utility concept of affiliation also provides a sufficient basis to build representations of such relationships. In the case of a reciprocal dyadic relationship, such as a friendship, the most straightforward approach within the adopted utility framework would be to have two separate 
affiliative representations encoding the relationship (e.g. Agent A positively weights the utility of Agent B and Agent B positively weights the utility of Agent A).

Representing many individual affiliations would be an inefficient way to approach representing large social groups, however. Instead, infants may conceive of social groups as categories for which one property of category members is that they are affiliated with all other members of that category. Thus each group member would place some weight on other group members' rewards when calculating the value of their own potential actions (Figure 1).

This proposal bears substantial similarity to the hypothesis that humans are equipped with a "coalitional psychology" or group-based intuitive sociology, in that both views suggest people represent social groups in a domain-specific way that prioritizes information about the group members' relationships (Cikara, 2020; Dunham, 2018; Hirschfeld, 2001; Pietraszewski, 2013; Rhodes, 2013; Tooby \& Cosmides, 2010). Like coalitional views, the proposal that infants can represent categories based on mutual utility adoption is consistent with evidence for infants' expectation of ingroup support (Jin \& Baillargeon, 2017; Pun et al., 2021). The main difference between the current proposal and most versions of coalitional psychology is that the latter hypothesize that humans have evolved dedicated cognitive systems for representing social groups, whereas the current proposal suggests that social categories with domain-specific affiliative features can be built from the same mental algorithms that support representations of simple, unidirectional social affiliation, which are in turn built from our intuitive theory of individual agents. It bases group cognition solely on the augmented view of naive utility calculus proposed here, and domain-general capacities for categorization.

This proposal also accounts for the apparent fact that not all categories of people are treated as affiliative social groups (Rabbie \& Horwitz, 1988). Some theories hold that social group allegiance stems from mere membership in any distinct category of people (Abrams \& Hogg, 1990; Dunham, 2018; Tajfel \& Turner, 1986). This seems unlikely, however, given that categories of people can be formed from an infinite number of attributes, not all of which covary with our concern for others' welfare. I am a member of the category of people born at 3:52 $\mathrm{AM}^{2}$, but I do not weigh the utility of other members of this category more highly than that of people born at other times of the day. There is also evidence that children's and adults' "minimal" group favoritism stems from the inference that, within the experimental context, minimal group members are likely to promote the utility of their ingroup; when this expectation is explicitly deflated, minimal group preferences diminish or disappear (Locksley, Ortiz \& Hepburn, 1980; Misch, Paulus \& Dunham, in press; Rabbie, Schot \& Visser, 1989; Yamagishi \& Kiyonari, 2000;

\footnotetext{
${ }^{2}$ Just kidding. I have no idea what time of day I was born, which is kind of the point.
} 
see also Patterson \& Bigler, 2006). Instead of being an automatically entailed consequence of social categorization, then, affiliation toward other group members can be assigned as a categorical attribute of some collections of people and not others.

One unresolved issue is how an observer would know when to attribute prosociality to group affiliation, rather than dyadic dynamics. Would an act of helping a category member always be taken as evidence of the existence and strength of affiliation with a social group?

\section{Similarity and Social Groups}

Affiliation toward the group need not be the only characteristic of a category, of course. For cases in which group members share other similarities, information about those similarities alone could support expectations of affiliation and prosocial behavior (Vélez \& Gweon, 2020). Reliable covariation between affiliation and similarity of a certain feature type might also lead to the formation of overhypotheses: expectations that new instances of the same type of similarity will also signal affiliation (Dewar \& Xu, 2010). For example, after building up experience with sports teams whose members all wear the same jersey, children may automatically assume that a new group of people wearing matching jerseys will also constitute a team.

Similarity may also impact estimates of the likelihood of shared utility. When similarity indicates a commonly desired goal, particularly one that is not zero sum, it signals an opportunity for mutual utility adoption (e.g. someone to go to the opera with). This kind of inference to shared utility may be rare in infancy but become more prevalent as children develop a stronger capacity for prospection, and a larger repertoire of long term goals or preferences (Afshordi, 2019; Byrne \& Griffitt, 1966; Reaves \& Roberts, 1983; Vélez et al., 2019).

\section{Curiously Strong Group Markers}

Finally, infants may observe that some kinds of actions are frequently the focus of adopted or shared utility, and come to expect that similarity in these domains predicts affiliation. In other words: there are some things people tend to do together, and this may lead to the prediction that people who do these things similarly are friends. Two common joint activities are eating and talking (Clark, 1996; Rozin, 2004; Shutts, Kinzler, et al., 2013). Before infants understand why it's beneficial to cook and eat together, or how speaking a shared language achieves communication, they may simply notice the prevalence of coordinated behavior in these two domains. These observations may lead infants to form overhypotheses that individuals who eat similarly and speak similarly are likely to be affiliated (Liberman et al., 2016; Liberman et al., 2017b). This conjecture is consistent with the recent finding that older infants, but not younger ones with less social experience, expect individuals who express the same food preference, separately, to be affiliated (Liberman et al., 2021). Moreover, although 
infants do not always expect imitation or shared preferences - after all, even close social partners do not constantly mimic one another - they may expect that affiliated individuals eat similar foods and speak similar languages, as they very frequently do coordinate in these domains (Liberman et al., 2016). Thus, attributes like language and food preference may be strong indicators of affiliation for infants not because humans have evolved innate connections between these attributes and social group membership (Kinzler, et al., 2007; Liberman et al., 2017a; Spelke \& Kinzler, 2007), but rather because those behaviors are frequently the focus of shared utility, which forms the core of infants' concept of affiliation. One prediction this account makes is that any type of behavior could become associated with affiliation, if it is reliably observed in the context of affiliative social interactions.

\section{Relationship to the Development of Morality}

The concept of affiliation proposed here is concerned with when one individual has or will act on behalf of another. In contrast, a commonsense theory of morality is concerned with when one individual should act on behalf of another. The main implication of the adopted utility calculus model for the topic of moral development, discussed above, is that infants' preferences for prosocial actors need not reflect approval of individuals for acting as they should, but can instead reflect the inference that the prosocial actor either 1) has adopted the same unmet goals that the infant has, as a sympathetic bystander, or 2) may universally value all social partners' goals, including the infant's.

There may, however, also be a role for the adopted utility concept of affiliation in moral learning and development. First, infants are particularly good learners when they are surprised (Stahl \& Feigenson, 2015). On the adopted utility view, infants will be surprised when an actor fails to take their affiliate's goals or well-being into account, e.g. through selfish or harmful behavior. If, while surprised by these lapses in affiliation, infants see the affiliate or an observer respond negatively to the transgressor, they may be especially likely to learn that such acts, and the neglect of affiliation they reflect, result in social disapproval or punishment. Thus, infants' most powerful moral learning opportunities may be centered on acts that violate existing relationships. This may explain why children's view of morality is often markedly parochial (Bian et al., 2018; Bloom, 2013; Chalik \& Dunham, 2020; Fehr et al., 2008; Hamlin, Mahajan, et al., 2013; Rhodes \& Chalik, 2013). Much of early moral inference may center around the belief that one should always act in accordance with the degree of utility adoption expected under existing affiliative relationships (see also Misch et al., 2014; Tomasello, 2020).

Second, one proposed moral learning mechanism is that children first learn about their relationships and then learn how much to weigh others' utility in accordance with those 
relationships, following culturally specific norms (Kleiman-Weiner, et al., 2017). Instead, the process may initially operate in the other direction: infants and children first observe and establish specific affiliative relationships defined by each individual's weighting of the other's welfare, and then come to carve this affiliative space into relationship categories by recognizing patterns in those weights and the contexts in which they apply. Children may then use these categories to adjust their estimates of how much they ought to weigh others' welfare as they learn an abstract moral theory.

\section{Conclusion}

The idea that social relationships revolve around caring about one another's welfare is not new (Afshordi \& Liberman, in press; Baumeister \& Leary, 1995; Delton \& Robertson, 2016; Rhodes, 2013; Trivers, 1971). My goal here was to argue that, at the very beginning of human life, infants not only desire relationships with those who care about them, but understand affiliation primarily in terms of this dimension. Infants map social connections and evaluate others as potential social partners via their ability to understand when social partners cooperatively or altruistically adopt one another's goals. This concept of affiliation is compatible with computational models of the commonsense psychology humans use to make sense of others' actions in terms of underlying desires, beliefs, and effort. Moreover, the adopted utility calculus model of affiliation is consistent with many findings in the current literature investigating infants' social reasoning, and above I suggest several future tests of its robustness.

This proposed concept of affiliation is not incompatible with additional innate systems for coalitional or moral reasoning, but it may obviate the need for them given the current body of evidence. It is possible to build social group representations from the same computations I have hypothesized infants use to encode single, asymmetrical, dyadic affiliation. It is also possible that infants' preferences for helpful and fair individuals reflect inferences of the actors' broadly affiliative dispositions (as opposed to partiality), or infants' preference for agents who align with their own sympathetic desire for others to receive help. Such preferences would reflect building blocks of a moral sense, including concern for others' well-being and an ability to represent and recognize something akin to impartiality, while not requiring that infants have a sense of which actions are "right" and "wrong" in general, regardless of social context or target.

This proposal also suggests a diminished role for homophily in early affiliative reasoning, and reframes the basis for the prosocial function of imitation. Instead of building rapport through similarity, imitation is prosocial when it reflects the imitator's valuing of another's desired state of the world and a motivation to jointly achieve that state, much like an act of cooperation. This can explain why infants only sometimes infer affiliation or form preferences 
upon observing matching actions or choices (Mahajan \& Wynn, 2012; Powell \& Spelke, 2018a; Powell \& Spelke, 2018b; Wynn, 2016). At the same time, this explanation for the prosocial role of imitation suggests it need not be thought of as a "gadget," acquired through mechanisms for cultural learning (Heyes, 2018). Instead, prosocial functions of imitation flow directly from foundational social cognitive capacities for the rational interpretation of others' actions.

There are several important directions left unexplored by the current discussion. First, how might this concept of affiliation be used to reason about relationships beyond direct, prosocial connections? Can infants use inferences of utility adoption to make transitive inferences about affiliation (Choi \& Luo, 2015; Hamlin et al., 2011)? Do infants represent antagonistic relationships, conflict, and competitive outgroups as negative weights that an actor places on others' welfare, motivating acts of malice or aggression?

Second, what is the role of development? The first 18 months of life are a time of rapid cognitive development. If reasoning about affiliation is based on commonsense psychology, then changes in infants' psychological reasoning ought to be reflected in affiliative inferences reasoning on a similar timeline. There is also likely to be affiliation-specific learning. For example, around the end of their first year infants begin to expect that the targets of pro- and antisocial behavior will prefer helpers to hinderers, like the infants themselves (Fawcett \& Liszkowski, 2012; Hamlin et al., 2007; Kuhlmeier et al., 2003). What does this change reflect? Have infants learned that prosocial acts have a causal effect on the recipients' attitudes? Or have they merely learned the generalization that prosocial relationships are often reciprocal?

Future work should investigate the role of this concept of affiliation throughout the lifespan. Children use patterns of prosocial behavior to identify relationships (Afshordi, 2019; Liberman \& Shaw, 2017; Liberman \& Shaw, 2019), and use relationships to predict biased or obligatory prosociality (e.g. Mammen, et al., 2021; Olson \& Spelke, 2008; Rhodes, 2012). This suggests that, like infants, children see utility adoption as a core component of affiliation (Afshordi \& Liberman, in press). This concept may also continue to affect social preferences. For example, adults prefer to have friends and spouses who engage in favoritism, over impartial actors who value all people's concerns equally (Everett et al., 2018); is this because impartiality between friends and strangers violates an understanding of close relationships as defined by especially strong weighting of one another's rewards?

Finally, individual and cultural differences in experience are likely to impact the development of this concept and the intuitive theories in which it is embedded (Amir \& McAuliffe, 2020; Nielsen, et al., 2017; Shutts \& Kalish, in press; Tasimi, 2020). Learning may affect perceptions of the likelihood of egalitarian versus parochial motives, and of the stability of 
affiliation over time (de Guzman, et al., 2008 Weinfeld, et al., 1999). Trajectories of moral learning will lead to differences in beliefs about how relationships should relate to the value we place on others' welfare (Kleiman-Weiner, et al., 2017; Rhodes \& Wellman, 2017). It is my hope that understanding the fundamental nature of our concept of affiliation will help to ground investigations aimed at promoting healthy individual and group relationships.

\section{Acknowledgments}

I am grateful to Madison Pesowski, Hilary Richardson, Rebecca Saxe, Adena Schachner, Alexis Smith-Flores, Charles Kalish, Yarrow Dunham, and an anonymous reviewer for their generous and insightful feedback. I also thank the SAME Writing Group for motivational support and camaraderie.

\section{References}

Abrams, D. E., \& Hogg, M. A. (1990). Social identity theory: Constructive and critical advances. Springer-Verlag Publishing.

Afshordi, N. (2019). Children's inferences about friendship and shared preferences based on reported information. Child Development, 9o(3), 719-727.

Afshordi, N., \& Liberman, Z. (in press). Keeping friends in mind: Development of friendship concepts in early childhood. Social Development.

Amir, D., \& McAuliffe, K. (2020). Cross-cultural, developmental psychology: Integrating approaches and key insights. Evolution and Human Behavior, 41(5), 430-444.

Baillargeon, R., Scott, R. M., \& Bian, L. (2016). Psychological reasoning in infancy. Annual Review of Psychology, 67, 159-186.

Bakeman, R., \& Brownlee, J. R. (1980). The strategic use of parallel play: A sequential analysis. Child Development, 51(3) 873-878.

Baker, C. L., Jara-Ettinger, J., Saxe, R., \& Tenenbaum, J. B. (2017). Rational quantitative attribution of beliefs, desires and percepts in human mentalizing. Nature Human Behaviour, 1(4), 1-10.

Baker, C. L., Saxe, R., \& Tenenbaum, J. B. (2009). Action understanding as inverse planning. Cognition, 113(3), 329-349.

Barragan, R. C., \& Dweck, C. S. (2014). Rethinking natural altruism: Simple reciprocal interactions trigger children's benevolence. Proceedings of the National Academy of Sciences, 111(48), 17071-17074.

Baumeister, R. F., \& Leary, M. R. (1995). The need to belong: desire for interpersonal attachments as a fundamental human motivation. Psychological Bulletin, 117(3), 497-529. 
Beier, J. S., \& Spelke, E. S. (2012). Infants' developing understanding of social gaze. Child Development, 83(2), 486-496.

Belot, M., Crawford, V. P., \& Heyes, C. (2013). Players of Matching Pennies automatically imitate opponents' gestures against strong incentives. Proceedings of the National Academy of Sciences, $110(8), 2763-2768$.

Berger, N. I., \& Ingersoll, B. (2015). An evaluation of imitation recognition abilities in typically developing children and young children with autism spectrum disorder. Autism Research, 8(4), 442-453.

Bian, L., Sloane, S., \& Baillargeon, R. (2018). Infants expect ingroup support to override fairness when resources are limited. Proceedings of the National Academy of Sciences, 115(11), 2705-2710.

Billig, M., \& Tajfel, H. (1973). Social categorization and similarity in intergroup behaviour. European Journal of Social Psychology, 3(1), 27-52.

Bloom, P. (2013). Horrible children. In M. R. Banaji \& S. A. Gelman (Eds.), Navigating the social world: What infants, children, and other species can teach us (pp. 348-351). Oxford University Press.

Bowles, S., \& Gintis, H. (2011). A cooperative species. Princeton University Press.

Burns, M. P., \& Sommerville, J. (2014). “I pick you”: The impact of fairness and race on infants' selection of social partners. Frontiers in Psychology, 5, 93.

Byrne, D., \& Griffitt, W. (1966). A developmental investigation of the law of attraction. Journal of Personality and Social Psychology, 4(6), 699-702.

Carpenter, M. (2006). Instrumental, social, and shared goals and intentions in imitation. In S. J. Rogers \& J. H. G. Williams (Eds.), Imitation and the social mind: Autism and typical development (pp. 48-70). Guilford Press.

Carpenter, M., Uebel, J., \& Tomasello, M. (2013). Being mimicked increases prosocial behavior in 18-month-old infants. Child Development, 84(5), 1511-1518.

Chalik, L., \& Dunham, Y. (2020). Beliefs about moral obligation structure children's social category-based expectations. Child Development, 91(1), e108-e119.

Chartrand, T. L., \& Bargh, J. A. (1999). The chameleon effect: the perception-behavior link and social interaction. Journal of Personality and Social Psychology, 76(6), 893-910.

Chartrand, T. L., \& Lakin, J. L. (2013). The antecedents and consequences of human behavioral mimicry. Annual Review of Psychology, 64, 285-308.

Choi, Y. J., \& Luo, Y. (2015). 13-month-olds' understanding of social interactions. Psychological Science, 26(3), 274-283. 
Cikara, M. (2020, December 17). Causes and consequences of coalitional cognition. https://doi.org/10.31219/osf.io/ktpf7

Clark, H. H. (1996). Using language. Cambridge University Press.

Cook, R., Bird, G., Lünser, G., Huck, S., \& Heyes, C. (2012). Automatic imitation in a strategic context: players of rock-paper-scissors imitate opponents' gestures. Proceedings of the Royal Society B: Biological Sciences, 279(1729), 780-786.

Csibra, G., Gergely, G., Bı́ ró, S., Koos, O., \& Brockbank, M. (1999). Goal attribution without agency cues: the perception of 'pure reason' in infancy. Cognition, 72(3), 237-267.

Davidov, M., Zahn-Waxler, C., Roth-Hanania, R., \& Knafo, A. (2013). Concern for others in the first year of life: Theory, evidence, and avenues for research. Child Development Perspectives, 7 (2), 126-131.

Dawkins, M.B., Sloane, S., \& Baillargeon, R. (2019). Do infants in the first year of life expect equal resource allocations?. Frontiers in Psychology, 10, 116.

de Guzman, M. R. T., Carlo, G., \& Pope Edwards, C. (2008). Prosocial behaviors in context: Examining the role of children's social companions. International Journal of Behavioral Development, 32(6), 522-530.

DeJesus, J. M., Rhodes, M., \& Kinzler, K. D. (2014). Evaluations versus expectations: Children's divergent beliefs about resource distribution. Cognitive Science, 38(1), 178-193.

Delton, A. W., \& Robertson, T. E. (2016). How the mind makes welfare tradeoffs: Evolution, computation, and emotion. Current Opinion in Psychology, 7, 12-16.

DesChamps, T. D., Eason, A. E., \& Sommerville, J. A. (2016). Infants associate praise and admonishment with fair and unfair individuals. Infancy, 21(4), 478-504.

Deutsch, M., \& Gerard, H. B. (1955). A study of normative and informational social influences upon individual judgment. The Journal of Abnormal and Social psychology, 51(3), 629-636.

Dewar, K. M., \& Xu, F. (2010). Induction, overhypothesis, and the origin of abstract knowledge: Evidence from 9-month-old infants. Psychological Science, 21(12), 1871-1877.

Dunham, Y. (2018). Mere membership. Trends in Cognitive Sciences, 22(9), 780-793.

Everett, J. A., Faber, N. S., Savulescu, J., \& Crockett, M. J. (2018). The costs of being consequentialist: Social inference from instrumental harm and impartial beneficence. Journal of Experimental Social Psychology, 79, 200-216.

Fawcett, C., \& Gredebäck, G. (2013). Infants use social context to bind actions into a collaborative sequence. Developmental Science, 16(6), 841-849. 
Fawcett, C., \& Liszkowski, U. (2012). Infants anticipate others' social preferences. Infant and Child Development, 21(3), 239-249.

Fawcett, C. A., \& Markson, L. (2010). Similarity predicts liking in 3-year-old children. Journal of Experimental Child Psychology, 105(4), 345-358.

Fehr, E., Bernhard, H., \& Rockenbach, B. (2008). Egalitarianism in young children. Nature, 454(7208), 1079-1083.

Fehr, E., \& Fischbacher, U. (2003). The nature of human altruism. Nature, 425(6960), 785-791.

Fiske, A. P. (1992). The four elementary forms of sociality: framework for a unified theory of social relations. Psychological Review, 99(4), 689-723.

Gelman, S. A., \& Legare, C. H. (2011). Concepts and folk theories. Annual Review of Anthropology, 40, 379-398.

Geraci, A., \& Surian, L. (2011). The developmental roots of fairness: Infants' reactions to equal and unequal distributions of resources. Developmental Science, 14(5), 1012-1020.

Gergely, G., \& Csibra, G. (2003). Teleological reasoning in infancy: The nave theory of rational action. Trends in Cognitive Sciences, 7(7), 287-292.

Gopnik, A., \& Wellman, H. M. (1992). Why the child's theory of mind really is a theory. Mind \& Language, $7(1-2), 145^{-171 .}$

Hamann, K., Warneken, F., \& Tomasello, M. (2012). Children's developing commitments to joint goals. Child Development, 83(1), 137-145.

Hamlin, J. K. (2013a). Moral judgment and action in preverbal infants and toddlers: Evidence for an innate moral core. Current Directions in Psychological Science, 22(3), 186-193.

Hamlin, J. K. (2013b). Failed attempts to help and harm: Intention versus outcome in preverbal infants' social evaluations. Cognition, 128(3), 451-474.

Hamlin, J. K., Mahajan, N., Liberman, Z., \& Wynn, K. (2013). Not like me= bad: Infants prefer those who harm dissimilar others. Psychological Science, 24(4), 589-594.

Hamlin, J. K., Ullman, T., Tenenbaum, J., Goodman, N., \& Baker, C. (2013). The mentalistic basis of core social cognition: Experiments in preverbal infants and a computational model. Developmental Science, 16(2), 209-226.

Hamlin, J. K., \& Wynn, K. (2011). Young infants prefer prosocial to antisocial others. Cognitive Development, 26(1), 30-39.

Hamlin, J. K., Wynn, K., \& Bloom, P. (2007). Social evaluation by preverbal infants. Nature, 45O(7169), 557-559. 
Hamlin, J. K., Wynn, K., Bloom, P., \& Mahajan, N. (2011). How infants and toddlers react to antisocial others. Proceedings of the National Academy of Sciences, 108(50), 19931-19936.

Haun, D., \& Over, H. (2015). Like me: A homophily-based account of human culture. In T. Breyer (Ed.) Epistemological dimensions of evolutionary psychology (pp. 117-130). Springer, New York, NY.

Hepach, R., Vaish, A., \& Tomasello, M. (2012). Young children are intrinsically motivated to see others helped. Psychological Science, 23(9), 967-972.

Hepach, R., Vaish, A., \& Tomasello, M. (2013). A new look at children's prosocial motivation. Infancy, 18(1), 67-90.

Heyes, C. (2018). Cognitive gadgets: The cultural evolution of thinking. Harvard University Press.

Hirschfeld, L. A. (2001). On a folk theory of society: Children, evolution, and mental representations of social groups. Personality and Social Psychology Review, 5(2), 107-117.

Hoehl, S., Keupp, S., Schleihauf, H., McGuigan, N., Buttelmann, D., \& Whiten, A. (2019). 'Over-imitation': A review and appraisal of a decade of research. Developmental Review, 51, 90-108.

Howard, R. M., Spokes, A. C., Mehr, S. A., \& Krasnow, M. (2018). Welfare tradeoff psychology is present in children and adults. https://doi.org/10.31234/osf.io/6daeg

Hsu, H. C., \& Lavelli, M. (2005). Perceived and observed parenting behavior in American and Italian first-time mothers across the first 3 months. Infant Behavior and Development, 28(4), 503-518.

Hurwitz, E., Brady, T. F., \& Schachner, A. (2019). Detecting social transmission in the design of artifacts via inverse planning. In A. K. Goel, C. M. Seifert, \& C. Freska (Eds.), Proceedings of the 41st Annual Conference of the Cognitive Science Society (pp. 457-463). Cognitive Science Society.

Jara-Ettinger, J., Gweon, H., Schulz, L. E., \& Tenenbaum, J. B. (2016). The naïve utility calculus: Computational principles underlying commonsense psychology. Trends in Cognitive Sciences, $20(8), 589-604$.

Jara-Ettinger, J., Gweon, H., Tenenbaum, J. B., \& Schulz, L. E. (2015). Children's understanding of the costs and rewards underlying rational action. Cognition, 14O, 14-23. 
Jara-Ettinger, J., Schulz, L. E., \& Tenenbaum, J. B. (2020). The naive utility calculus as a unified, quantitative framework for action understanding. Cognitive Psychology, 123, 101334 .

Jin, K. S., \& Baillargeon, R. (2017). Infants possess an abstract expectation of ingroup support. Proceedings of the National Academy of Sciences, 114(31), 8199-8204.

Jin, K. S., Houston, J. L., Baillargeon, R., Groh, A. M., \& Roisman, G. I. (2018). Young infants expect an unfamiliar adult to comfort a crying baby: Evidence from a standard violation-of-expectation task and a novel infant-triggered-video task. Cognitive Psychology, 102, 1-20.

Johnson, S. C., Dweck, C. S., \& Chen, F. S. (2007). Evidence for infants' internal working models of attachment. Psychological Science, 18(6), 501.

Jones, B., \& Rachlin, H. (2006). Social discounting. Psychological Science, 17(4), 283-286.

Kanakogi, Y., Inoue, Y., Matsuda, G., Butler, D., Hiraki, K., \& Myowa-Yamakoshi, M. (2017). Preverbal infants affirm third-party interventions that protect victims from aggressors. Nature Human Behaviour, 1(2), 1-7.

Kinzler, K. D., Dupoux, E., \& Spelke, E. S. (2007). The native language of social cognition. Proceedings of the National Academy of Sciences, 104(30), 12577-12580.

Kleiman-Weiner, M., Ho, M. K., Austerweil, J. L., Littman, M. L., \& Tenenbaum, J. B. (2016). Coordinate to cooperate or compete: abstract goals and joint intentions in social interaction. In A. Papafragou, D. Grodner, D. Mirman, \& J. C. Trueswell (Eds.), Proceedings of the 38th Annual Conference of the Cognitive Science Society (pp.1679-1684). Cognitive Science Society.

Kleiman-Weiner, M., Saxe, R., \& Tenenbaum, J. B. (2017). Learning a commonsense moral theory. Cognition, 167, 107-123.

Kuhlmeier, V., Wynn, K., \& Bloom, P. (2003). Attribution of dispositional states by 12-month-olds. Psychological Science, 14(5), $402-408$.

Laland, K. N. (2004). Social learning strategies. Animal Learning \& Behavior, 32(1), 4-14.

Liberman, Z., Kinzler, K. D., \& Woodward, A. L. (2014). Friends or foes: Infants use shared evaluations to infer others' social relationships. Journal of Experimental Psychology: General, 143(3), 966-971.

Liberman, Z., Kinzler, K. D., \& Woodward, A. L. (2018). The early social significance of shared ritual actions. Cognition, 171, 42-51.

Liberman, Z., Kinzler, K. D., \& Woodward, A. L. (2021). Origins of homophily: Infants expect people with shared preferences to affiliate. Cognition, 212, 104695. 
Liberman, Z., \& Shaw, A. (2017). Children use partial resource sharing as a cue to friendship. Journal of Experimental Child Psychology, 159, 96-109.

Liberman, Z., \& Shaw, A. (2019). Children use similarity, propinquity, and loyalty to predict which people are friends. Journal of Experimental Child Psychology, 184, 1-17.

Liberman, Z., Woodward, A. L., \& Kinzler, K. D. (2017a). The origins of social categorization. Trends in Cognitive Sciences, 21(7), 556-568.

Liberman, Z., Woodward, A. L., \& Kinzler, K. D. (2017b). Preverbal infants infer third-party social relationships based on language. Cognitive Science, 41, 622-634.

Liberman, Z., Woodward, A. L., Sullivan, K. R., \& Kinzler, K. D. (2016). Early emerging system for reasoning about the social nature of food. Proceedings of the National Academy of Sciences, 113(34), 9480-9485.

Liu, S., Brooks, N. B., \& Spelke, E. S. (2019). Origins of the concepts cause, cost, and goal in prereaching infants. Proceedings of the National Academy of Sciences, 116(36), 17747-17752.

Liu, S., Ullman, T. D., Tenenbaum, J. B., \& Spelke, E. S. (2017). Ten-month-old infants infer the value of goals from the costs of actions. Science, 358(6366), 1038-1041.

Locksley, A., Ortiz, V., \& Hepburn, C. (1980). Social categorization and discriminatory behavior: Extinguishing the minimal intergroup discrimination effect. Journal of Personality and Social Psychology, 39(5), 773-783.

Lucca, K., Pospisil, J., \& Sommerville, J. A. (2018). Fairness informs social decision making in infancy. PLoS One, 13(2), e0192848.

Luo, Y., \& Baillargeon, R. (2007). Do 12.5-month-old infants consider what objects others can see when interpreting their actions?. Cognition, 105(3), 489-512.

Luo, Y., \& Johnson, S. C. (2009). Recognizing the role of perception in action at 6 months. Developmental Science, 12(1), 142-149.

Mahajan, N., \& Wynn, K. (2012). Origins of “us" versus "them": Prelinguistic infants prefer similar others. Cognition, 124(2), 227-233.

Mammen, M., Köymen, B., \& Tomasello, M. (2021). Young children's moral judgments depend on the social relationship between agents. Cognitive Development, 57, 100973.

Margoni, F., \& Surian, L. (2018). Infants' evaluation of prosocial and antisocial agents: A meta-analysis. Developmental Psychology, 54(8), 1445.

McGuigan, N., \& Whiten, A. (2009). Emulation and "overemulation" in the social learning of causally opaque versus causally transparent tool use by 23 -and 30 -month-olds. Journal of Experimental Child Psychology, 104(4), 367-381. 
Meltzoff, A. N. (1990). Foundations for developing a concept of self: The role of imitation in relating self to other and the value of social mirroring, social modeling, and self practice in infancy. In D. Cicchetti \& M. Beeghly (Eds.), The John D. and Catherine T. MacArthur foundation series on mental health and development. The self in transition: Infancy to childhood (p. 139-164). University of Chicago Press.

Meristo, M., Strid, K., \& Surian, L. (2016). Preverbal infants' ability to encode the outcome of distributive actions. Infancy, 21(3), 353-372.

Meristo, M., \& Surian, L. (2013). Do infants detect indirect reciprocity? Cognition, 129(1), 102-113.

Misch, A., Over, H., \& Carpenter, M. (2014). Stick with your group: Young children's attitudes about group loyalty. Journal of Experimental Child Psychology, 126, 19-36.

Misch, A., Paulus, M., \& Dunham, Y. (in press). Anticipation of future cooperation eliminates minimal ingroup bias in children and adults. Journal of Experimental Psychology: General.

Moran, G., Krupka, A., Tutton, A., \& Symons, D. (1987). Patterns of maternal and infant imitation during play. Infant Behavior and Development, 1O(4), 477-491.

Naber, M., Pashkam, M. V., \& Nakayama, K. (2013). Unintended imitation affects success in a competitive game. Proceedings of the National Academy of Sciences, 110(50), 20046-20050.

Nielsen, M. (2006). Copying actions and copying outcomes: social learning through the second year. Developmental Psychology, 42(3), 555.

Nielsen, M., Haun, D., Kärtner, J., \& Legare, C. H. (2017). The persistent sampling bias in developmental psychology: A call to action. Journal of Experimental Child Psychology, 162, 31-38.

Olson, K. R., \& Shaw, A. (2011). 'No fair, copycat!': what children's response to plagiarism tells us about their understanding of ideas. Developmental Science, 14(2), 431-439.

Olson, K. R., \& Spelke, E. S. (2008). Foundations of cooperation in young children. Cognition, 108(1), 222-231.

Over, H. (2020). The social function of imitation in development. Annual Review of Developmental Psychology, 2, 93-109.

Over, H., \& Carpenter, M. (2009). Priming third-party ostracism increases affiliative imitation in children. Developmental science, 12(3), F1-F8. 
Over, H., \& Carpenter, M. (2012). Putting the social into social learning: explaining both selectivity and fidelity in children's copying behavior. Journal of Comparative Psychology, 126(2), 182-192.

Papeo, L., Goupil, N., \& Hochmann, J. (2020). Visual perception grounding of social cognition in preverbal infants. https://doi.org/10.31219/osf.io/v7y9x

Papoušek, M., \& Papoušek, H. (1989). Forms and functions of vocal matching in interactions between mothers and their precanonical infants. First Language, 9(6), 137-157.

Parten, M. B. (1933). Social play among preschool children. The Journal of Abnormal and Social Psychology, 28(2), 136-147.

Patterson, M. M., \& Bigler, R. S. (2006). Preschool children's attention to environmental messages about groups: Social categorization and the origins of intergroup bias. Child Development, $77(4), 847-860$.

Paulus, M., \& Moore, C. (2014). The development of recipient-dependent sharing behavior and sharing expectations in preschool children. Developmental Psychology, 5O(3), 914-921.

Pesowski, M., Quy, A., Lee, M., \& Schachner, A. (2020). Children use inverse planning to detect social transmission in design of artifacts. In S. Denison, M. Mack, Y. Xu, \& B. C. Armstrong (Eds.), The Proceedings of the 42nd Annual Meeting of the Cognitive Science Society (pp. 845-851). Cognitive Science Society.

Pietraszewski, D. (2013). What is group psychology? Adaptations for mapping shared intentional stances. In M. R. Banaji \& S. A. Gelman (Eds.), Navigating the social world: What infants, children, and other species can teach us (pp. 253-257). Oxford University Press.

Powell, L. J., \& Spelke, E. S. (2013). Preverbal infants expect members of social groups to act alike. Proceedings of the National Academy of Sciences, 110(41), E3965-E3972.

Powell, L. J., \& Spelke, E. (2017). The role of perceptual access in infants' third party evaluations of imitation. https://doi.org/10.31234/osf.io/63tyq

Powell, L. J., \& Spelke, E. S. (2018a). Human infants' understanding of social imitation: Inferences of affiliation from third party observations. Cognition, 170, 31-48.

Powell, L. J., \& Spelke, E. S. (2018b). Third-party preferences for imitators in preverbal infants. Open Mind, 2(2), 61-71.

Pun, A., Birch, S. A., \& Baron, A. S. (2021). The power of allies: Infants' expectations of social obligations during intergroup conflict. Cognition, 211, 104630.

Rabbie, J. M., \& Horwitz, M. (1988). Categories versus groups as explanatory concepts in intergroup relations. European Journal of Social Psychology, 18(2), 117-123. 
Rabbie, J. M., Schot, J. C., \& Visser, L. (1989). Social identity theory: A conceptual and empirical critique from the perspective of a behavioural interaction model. European Journal of Social Psychology, 19(3), 171-202.

Ramenzoni, V. C., \& Liszkowski, U. (2016). The social reach: 8-month-olds reach for unobtainable objects in the presence of another person. Psychological Science, 27(9), 1278-1285.

Reaves, J. Y., \& Roberts, A. (1983). The effect of type of information on children's attraction to peers. Child Development, 1024-1031.

Rhodes, M. (2012). Naïve theories of social groups. Child Development, 83(6), 1900-1916.

Rhodes, M. (2013). How two intuitive theories shape the development of social categorization. Child Development Perspectives, 7(1), 12-16.

Rhodes, M., \& Chalik, L. (2013). Social categories as markers of intrinsic interpersonal obligations. Psychological Science, 24(6), 999-1006.

Rhodes, M., \& Wellman, H. (2017). Moral learning as intuitive theory revision. Cognition, 167, 191-200.

Roberts, S. O., Williams, A. D., \& Gelman, S. A. (2017). Children's and adults' predictions of black, white, and multiracial friendship patterns. Journal of Cognition and Development, 18(2), 189-208.

Rochat, P., Querido, J. G., \& Striano, T. (1999). Emerging sensitivity to the timing and structure of protoconversation in early infancy. Developmental Psychology, 35(4), 950-957.

Roth-Hanania, R., Davidov, M., \& Zahn-Waxler, C. (2011). Empathy development from 8 to 16 months: Early signs of concern for others. Infant Behavior and Development, 34(3), 447-458.

Rozin, P. (2004). Sociocultural influences on human food selection. In E. D.Capaldi (Ed.), Why we eat what we eat: The psychology of eating (pp. 233-263). American Psychological Association.

Rubin, K. H., Watson, K. S., \& Jambor, T. W. (1978). Free-play behaviors in preschool and kindergarten children. Child Development, 49(2), 534-536.

Salvadori, E., Blazsekova, T., Volein, A., Karap, Z., Tatone, D., Mascaro, O., \& Csibra, G. (2015). Probing the strength of infants' preference for helpers over hinderers: Two replication attempts of Hamlin and Wynn (2011). PLoS One, 10(11), e0140570.

Saxe, R., Carey, S., \& Kanwisher, N. (2004). Understanding other minds: linking developmental psychology and functional neuroimaging. Annual Review of Psychology, 55, 87-124. 
Schachner, A., \& Carey, S. (2013). Reasoning about 'irrational' actions: When intentional movements cannot be explained, the movements themselves are seen as the goal. Cognition, 129(2), 309-327.

Schlingloff, L., Csibra, G., \& Tatone, D. (2020). Do 15-month-old infants prefer helpers? A replication of Hamlin et al.(2007). Royal Society Open Science, 7(4), 191795.

Schmidt, M. F., \& Sommerville, J. A. (2011). Fairness expectations and altruistic sharing in 15-month-old human infants. PLoS One, 6(10), e23223.

Scott, R. M., \& Baillargeon, R. (2013). Do infants really expect agents to act efficiently? A critical test of the rationality principle. Psychological Science, 24(4), 466-474.

Shaw, A. (2013). Beyond "to share or not to share" The impartiality account of fairness. Current Directions in Psychological Science, 22(5), 413-417.

Shaw, A., DeScioli, P., \& Olson, K. R. (2012). Fairness versus favoritism in children. Evolution and Human Behavior, 33(6), 736-745.

Shutts, K. \& Kalish, C. W. (in press). Intuitive sociology. In J. Lockman (Ed.), Advances in child development and behavior (Vol. 61). Elsevier.

Shutts, K., Kinzler, K. D., \& DeJesus, J. M. (2013). Infants' and children's social learning about foods: Previous research and new prospects. Developmental Psychology, 49(3), 419-425.

Shutts, K., Roben, C. K. P., \& Spelke, E. S. (2013). Children's use of social categories in thinking about people and social relationships. Journal of Cognition and Development, 14(1), $35-62$.

Skerry, A. E., Carey, S. E., \& Spelke, E. S. (2013). First-person action experience reveals sensitivity to action efficiency in prereaching infants. Proceedings of the National Academy of Sciences, 110(46), 18728-18733.

Skerry, A. E., \& Spelke, E. S. (2014). Preverbal infants identify emotional reactions that are incongruent with goal outcomes. Cognition, 13O(2), 204-216.

Sloane, S., Baillargeon, R., \& Premack, D. (2012). Do infants have a sense of fairness?. Psychological Science, 23(2), 196-204.

Smith, C. E., Blake, P. R., \& Harris, P. L. (2013). I should but I won't: Why young children endorse norms of fair sharing but do not follow them. PLoS One, 8(3), e59510.

Sommerville, J. A., Schmidt, M. F., Yun, J. E., \& Burns, M. (2013). The development of fairness expectations and prosocial behavior in the second year of life. Infancy, 18(1), 40-66.

Spelke, E. S. (1990). Principles of object perception. Cognitive Science, 14(1), 29-56.

Spelke, E. S., \& Kinzler, K. D. (2007). Core knowledge. Developmental Science, 1o(1), 89-96. 
Stahl, A. E., \& Feigenson, L. (2015). Observing the unexpected enhances infants' learning and exploration. Science, 348(6230), 91-94.

Strid, K., \& Meristo, M. (2020). Infants Consider the Distributor's Intentions in Resource Allocation. Frontiers in Psychology, 11, 2806.

Tajfel, H., \& Turner, J. C. (1986). The social identity theory of intergroup behavior. In S. Worchel, \& W. G. Austin (Eds.), Psychology of intergroup relations (pp. 7-24). Nelson-Hall.

Tasimi, A. (2020). Connecting the dots on the origins of social knowledge. Perspectives on Psychological Science, 15(2), 397-410.

Tatone, D., Geraci, A., \& Csibra, G. (2015). Giving and taking: Representational building blocks of active resource-transfer events in human infants. Cognition, 137, 47-62.

Thiele, M., Hepach, R., Michel, C., Gredebäck, G., \& Haun, D. B. (2021). Social interaction targets enhance $13^{-}$-month-old infants' associative learning. Infancy. https://doi.org/10.1111/infa.12393

Thomas, A. J., \& Sarnecka, B. W. (2019). Infants choose those who defer in conflicts. Current Biology, 29(13), 2183-2189.

Thomas, A., Saxe, R., \& Spelke, E. (2020, Jul 29-Aug 1). Infants use imitation but not comforting or social synchrony to evaluate those in social interactions. [Conference presentation abstract]. 42nd annual meeting of the Cognitive Science Society, Virtual.

Ting, F., Dawkins, M. B., Stavans, M., \& Baillargeon, R. (2019). Principles and concepts in early moral cognition. In J. Decety (Ed.), The social brain: A developmental perspective. MIT Press.

Tomasello, M. (2020). The moral psychology of obligation. Behavioral and Brain Sciences, 43, E56. doi:10.1017/So140525X19001742

Tomasello, M., Carpenter, M., Call, J., Behne, T., \& Moll, H. (2005). Understanding and sharing intentions: The origins of cultural cognition. Behavioral and Brain Sciences, 28(5), 675-691.

Tooby, J., \& Cosmides, L. (2010). Groups in mind: The coalitional roots of war and morality. In C. Boesch, et al., (Eds.), Human morality and sociality: Evolutionary and comparative perspectives (pp. 191-234). Macmillan International Higher Education.

Trevarthen, C., \& Aitken, K. J. (2001). Infant intersubjectivity: Research, theory, and clinical applications. Journal of Child Psychology and Psychiatry, 42(1), 3-48.

Trivers, R. L. (1971). The evolution of reciprocal altruism. The Quarterly Review of Biology, 46(1), 35-57. 
Tronick, E., Als, H., Adamson, L., Wise, S., \& Brazelton, T. B. (1978). The infant's response to entrapment between contradictory messages in face-to-face interaction. Journal of the American Academy of Child Psychiatry, 17(1), 1-13.

Ullman, T. D., Baker, C. L., Macindoe, O., Evans, O., Goodman, N. D., \& Tenenbaum, J. B. (2010). Help or hinder: Bayesian models of social goal inference. Advances in Neural Information Processing Systems, 22, 1874-1882.

Ullman, T. D., \& Tenenbaum, J. B. (2020). Bayesian models of conceptual development: Learning as building models of the world. Annual Review of Developmental Psychology, 2, 533-558.

Uzgiris, I. C. (1981). Two functions of imitation during infancy. International Journal of Behavioral Development, 4(1), 1-12.

Vaish, A., Carpenter, M., \& Tomasello, M. (2009). Sympathy through affective perspective taking and its relation to prosocial behavior in toddlers. Developmental Psychology, 45(2), 534 .

Vaquera, E., \& Kao, G. (2008). Do you like me as much as I like you? Friendship reciprocity and its effects on school outcomes among adolescents. Social Science Research, 37(1), 55-72.

Vélez, N., Bridgers, S., \& Gweon, H. (2019). The rare preference effect: Statistical information influences social affiliation judgments. Cognition, 192, 103994.

Vélez, N., \& Gweon, H. (2020). Preschoolers use minimal statistical information about social groups to infer the preferences and group membership of individuals. In S. Denison, M. Mack, Y. Xu, \& B. C. Armstrong (Eds.), The Proceedings of the 42nd Annual Meeting of the Cognitive Science Society (pp. 227-233). Cognitive Science Society.

Warneken, F., Hare, B., Melis, A. P., Hanus, D., \& Tomasello, M. (2007). Spontaneous altruism by chimpanzees and young children. PLoS Biology, 5(7), e184.

Warneken, F., \& Tomasello, M. (2006). Altruistic helping in human infants and young chimpanzees. Science, 311(5765), 1301-1303.

Warneken, F., \& Tomasello, M. (2007). Helping and cooperation at 14 months of age. Infancy, 11(3), 271-294.

Warneken, F., \& Tomasello, M. (2009). The roots of human altruism. British Journal of Psychology, 10o(3), 455-471.

Watson-Jones, R. E., \& Legare, C. H. (2016). The social functions of group rituals. Current Directions in Psychological Science, 25(1), 42-46.

Watson-Jones, R. E., Whitehouse, H., \& Legare, C. H. (2016). In-group ostracism increases high-fidelity imitation in early childhood. Psychological Science, 27(1), 34-42. 
Weinfield, N. S., Sroufe, L. A., Egeland, B., \& Carlson, E. A. (1999). The nature of individual differences in infant-caregiver attachment. Handbook of attachment: Theory, research, and clinical applications, 17, 68-88.

Woo, B. M., \& Spelke, E. S. (2020a). How to help best: Infants' changing understanding of multistep actions informs their evaluations of helping. In S. Denison, M. Mack, Y. Xu, \& B. C. Armstrong (Eds.), The Proceedings of the 42nd Annual Meeting of the Cognitive Science Society (pp. 384-390). Cognitive Science Society.

Woo, B. M., \& Spelke, E. (2020). Infants' social evaluations depend on the beliefs guiding acts of helping. https://doi.org/10.31234/osf.io/eczgp

Woodward, A. L. (1998). Infants selectively encode the goal object of an actor's reach. Cognition, 69(1), 1-34.

Woodward, A. L., Sommerville, J. A., \& Guajardo, J. J. (2001). How infants make sense of intentional action. In B. F. Malle, L. J. Moses, \& D. A. Baldwin (Eds.), Intentions and intentionality: Foundations of social cognition (pp. 149-169). MIT Press.

Wynn, K. (2016). Origins of value conflict: Babies do not agree to disagree. Trends in Cognitive Sciences, 2O(1), 3-5.

Wynn, K., \& Bloom, P. (2014). The moral baby. In M. Killen \& J. G. Smetana (Eds.), Handbook of Moral Development (p. 435-453). Psychology Press.

Yamagishi, T., \& Kiyonari, T. (2000). The group as the container of generalized reciprocity. Social Psychology Quarterly, 63(2), 116-132.

Ziv, T., \& Sommerville, J. A. (2017). Developmental differences in infants' fairness expectations from 6 to 15 months of age. Child Development, 88(6), 1930-1951. 